\title{
Purpose Driven Competency Planning for Enterprise Modeling Projects
}

\author{
Janis Stirna ${ }^{1}$ and Anne Persson ${ }^{2}$ \\ ${ }^{1}$ Department of Computer and Systems Sciences, Stockholm University, Forum 100, \\ SE-1644 0, Kista, Sweden \\ js@dsv.su.se \\ ${ }^{2}$ University of Skövde, Informatics Research Centre, P.O. Box 408, \\ SE-541 28 Skövde, Sweden \\ anne.persson@his.se
}

\begin{abstract}
Much of the success of projects using Enterprise Modeling (EM) depends more on the quality of the process of modeling rather than on the method used. One important influence on the quality of the modeling process is the competency level of the experts responsible for the EM approach. Each EM project is, however, specific depending on the purpose of modeling, such as developing the business, ensuring the quality of business operations, and using EM as a problem solving tool. The objective of this paper is to discuss the core competency needs for the EM practitioner and to relate those needs to different purposes of EM.
\end{abstract}

Keywords: Enterprise Modeling, modeling practitioner, competence profile.

\section{Introduction}

Enterprise Modeling (EM) is a process where an integrated and negotiated model describing different aspects of an enterprise is created for the purposes of (1) developing the business, (2) ensuring the quality of business operations, and (3) using EM as a problem solving tool [1]. In [1 and 2] we have argued that EM usage is heavily influenced by a large number of situational factors, one of which is the intention behind its use. Knowledge about the purpose of a particular EM endeavor is essential when making decisions about which modeling language, way of working, tool support etc. is appropriate. It is important to bear in mind that organizations do not use EM methods only for the sake of using methods. They want to solve a particular business problem and EM is only one of several instruments in that problem solving process.

In [2] we have analyzed what requirements the different purposes of EM put on the EM project in terms of input models and documentation, models to be developed, EM language, EM process, EM tool, as well as enterprise model quality. EM usually is organized in the form of a project or it is a part of a larger, e.g. organizational or information system (IS) development, project.

Much of the success of projects using Enterprise Modeling depends more on the quality of the process of modeling rather than on the method used. One important 
influence on the quality of the modeling process is the competency level of the experts responsible for the EM approach. In [3] we defined a set of core competencies for the modeling practitioner and related these competencies to a detailed stereotype EM project process. However, since each EM project is specific depending on the purpose of modeling, this paper analyses how the purpose of EM influences competency requirements. Hence, we formulated the following research questions:

1. What are the relationships between the identified core competencies and the purposes of EM?

2. How can the core competencies be refined, if at all, based on these relationships?

The research focuses only on an enterprise modeling practitioner who is responsible for carrying out part of or the whole EM project process towards effectively achieving its goals.

The remainder of the paper is organized as follows. Section 2 discusses the concept of EM competency. In section 3 the research approach is presented. The main purposes of EM are outlined in section 4 while section 5 discusses the core competencies of the EM practitioner. In section 6 the core competencies are analyzed in relation to the purposes of EM and a refinement of the competencies is proposed. The paper ends with a discussion (section 7), related work (section 8), and some concluding remarks in section 9 .

\section{Competency - A Critical Resource to Achieve the Goals of EM}

The concept of competency is complex and can be defined in a number of ways. In [3] we argue that for the purposes of analyzing competency issues in EM we have to concentrate on four main aspects:

1) Knowledge - a person's factual knowledge about a specific subject matter, as a result of e.g. education.

2) Skills - a person's ability to actually use the knowledge to achieve goals.

3) Individual properties - a wide range of personal characteristics e.g. ability to communicate, intelligence, flexibility, integrity, ability to co-operate, courage etc.

4) Willingness to contribute competency - a person's attitude towards actually contributing her/his knowledge and skills to the achievement of goals other than her/his own.

In this paper we particularly target the competency of the modeling practitioner. In the following we give an overview of the key roles in EM.

Domain experts provide knowledge about different aspects of some organization in its current or perceived future state. They are responsible for the correctness and relevance of that knowledge in the context of the EM project. Most EM projects also have a project or problem "owner" - someone who is in charge of the problem domain, allocates resources, and has the authority to implement the decisions and designs developed by the EM project. 
Creation of the Enterprise Models using a participative approach needs to be supported by a modeling practitioner. The professional EM practitioner may take on a number of sub-roles, e.g. EM project leader, facilitator of a modeling session, and tool expert. As project leader, the modeling practitioner negotiates the goals for the modeling project and plans the modeling process together with the project or problem owner. A facilitator moderates each modeling session. In a session there can be more than one facilitator and also a tool expert. A larger modeling project will typically have several facilitators and tool experts forming a modeling practitioner team, which is headed by project leader. The team leader should be an experienced facilitator.

[4] summarizes that the main responsibility of the modeling practitioner is that (1) the models produced have good enough quality to accomplish the project goals; (2) that the chosen EM method is suitable for modeling the problem at hand and that (3) the method is effectively used to accomplish the project goals. This means not only to use the method's notation in a reasonable way but to also construct and to run a modeling process that makes the best of available resources, e.g. the knowledge and abilities of domain experts. The modeling practitioner is also responsible for making sure that the project resources are used in a way that enables the modeling project to be completed on time and in such a way that the goals are achieved.

The main challenge of the EM process is to ensure that the quality of its outcome is fit for the intended use. Potential outcomes of EM are, e.g., models, decisions and enhanced knowledge among those involved in the EM process. Since the EM process is highly intellectual, it is dependent on the competency of its participants. If the proper EM competency is not available in the EM process, the effects of EM will not appear. In this paper we focus on the competency of the EM practitioner.

\section{Research Approach}

The research contribution of this paper is based on a number of research efforts carried out since beginning of the 1990-ies and their resulting publications:

- Development of the Enterprise Knowledge Development (EKD) EM method [5],

- Extensive field work applying versions of EKD to a variety of problems,

- Interview studies involving experienced EM consultants and method developers.

The most influential application cases were, for the most part, carried out within international research projects financed by the European Commission. An overview of the cases is given in Table 1. The applications that contributed to this paper took place in the years 1993-2008. Their processes and their outcome were observed and analyzed. Collected data and experiences from method development, field work and interviews were analyzed. Two interview studies focusing on the intentional and situational factors that influence participatory EM and EM tool usage [1, 4, 7] were also carried out. In addition, EKD and its earlier versions have also been used in a number of smaller problem solving and organizational design cases at organizations such as e.g. Strömma AB (Sweden), Ericsson (Sweden), Livani District (Latvia), Riga Technical University (Latvia), University of Skövde (Sweden) and RRC College (Latvia). 
Table 1. Overview of main application cases

\begin{tabular}{|c|c|c|c|}
\hline Organization & Domain & Period & Problems addressed \\
\hline $\begin{array}{l}\text { British Aerospace, } \\
\text { UK }\end{array}$ & $\begin{array}{l}\text { Aircraft development and } \\
\text { production }\end{array}$ & $\begin{array}{l}1992- \\
1994\end{array}$ & Requirements Engineering \\
\hline $\begin{array}{l}\text { Telia AB, } \\
\text { Sweden }\end{array}$ & $\begin{array}{l}\text { Telecommunications } \\
\text { industry }\end{array}$ & 1996 & $\begin{array}{l}\text { Requirements validation } \\
\text { Project definition }\end{array}$ \\
\hline $\begin{array}{l}\text { Volvo Cars AB, } \\
\text { Sweden }\end{array}$ & Car manufacturing & $\begin{array}{l}1994- \\
1997\end{array}$ & Requirements engineering \\
\hline $\begin{array}{l}\text { Vattenfall AB, } \\
\text { Sweden }\end{array}$ & $\begin{array}{l}\text { Electrical power } \\
\text { industry }\end{array}$ & $\begin{array}{l}1996- \\
1999\end{array}$ & $\begin{array}{l}\text { Change management, Process development, } \\
\text { Competence management }\end{array}$ \\
\hline $\begin{array}{l}\text { Riga City Council, } \\
\text { Latvia }\end{array}$ & Public administration & $\begin{array}{l}2001- \\
2003\end{array}$ & $\begin{array}{l}\text { Development of vision and supporting } \\
\text { processes for knowledge management }\end{array}$ \\
\hline $\begin{array}{l}\text { Verbundplan } \\
\text { GmbH, Austria }\end{array}$ & $\begin{array}{l}\text { Electrical power } \\
\text { industry }\end{array}$ & $\begin{array}{l}2001- \\
2003\end{array}$ & $\begin{array}{l}\text { Development of vision and supporting } \\
\text { processes for knowledge management }\end{array}$ \\
\hline $\begin{array}{l}\text { Skaraborg } \\
\text { Hospital, Sweden }\end{array}$ & Health care & $\begin{array}{l}2004- \\
2007\end{array}$ & $\begin{array}{l}\text { Capturing knowledge assets and development } \\
\text { of a knowledge map of a knowledge } \\
\text { repository. }\end{array}$ \\
\hline $\begin{array}{l}\text { SYSteam AB, } \\
\text { Sweden }\end{array}$ & $\begin{array}{l}\text { Management } \\
\text { consulting }\end{array}$ & 2008 & $\begin{array}{l}\text { Development of a vision for an employee } \\
\text { knowledge management portal }\end{array}$ \\
\hline
\end{tabular}

Empirical data from modeling activities of the above mentioned types were documented as written notes and analyzed. Interviews with practitioners were transcribed and analyzed using Grounded Theory [6] data analysis. The data and analyses have then been used as input for a series of argumentative syntheses targeting:

1. Requirements on EM related to the purposes of using EM, reported in [2],

2. Core competencies of an EM practitioner, reported in [3], and

3. The relationship between core competencies and the purposes of EM, reported in this paper.

The goal of this series of analyses is to establish a line of research that addresses different aspects of EM from a purpose and situational perspective. Figure 1 illustrates the research process and resulting publications that lead up to this paper.

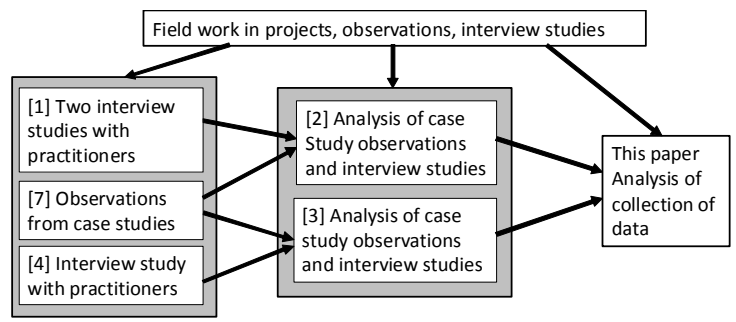

Fig. 1. The research process leading to this paper 


\section{Purpose of EM Projects}

In [1 and 2] we have argued that EM projects usually have the following purposes:

- To develop the business. This entails, e.g., developing business vision, strategies, redesigning business operations, developing the supporting information systems, etc. Business development is one of the most common purposes of EM. It frequently involves change management - determining how to achieve visions and objectives from the current state in organizations. Business process orientation is a specific case of business development - the organization wants to restructure/redesign its business operations.

- To ensure the quality of the business operations. This purpose primarily focuses on two issues: 1) sharing the knowledge about the business, its vision, and the way it operates, and 2) ensuring the acceptance of business decisions through committing the stakeholders to the decisions made. A motivation to adopt EM is to ensure the quality of operations. Two important success factors for ensuring quality are that stakeholders understand the business and that they accept/are committed to business decisions. Recently, organizations have taken an increased interest in Knowledge Management (KM), which concerns creating, maintaining and disseminating organizational knowledge between stakeholders. Sharing business knowledge becomes instrumental when organizations merge or collaborate in carrying out a business process. One aspect of this is terminology. EM has a role to play here as it aims to create a multifaceted "map" of the business as a common platform for communicating between stakeholders. One KM perspective is keeping employees informed with regard to how the business is carried out. Most modern organizations consider that the commitment of stakeholders to carry out business decisions is a critical success factor for achieving high quality business operations. Differences in opinion about the business must hence be resolved, requiring that communication between stakeholders be stimulated. EM, particularly using a participative approach, can be effective to obtain such commitment.

- To use EM as a problem solving tool. EM is here only used for supporting the discussion among a group of stakeholders trying to analyze a specific problem at hand. In some cases making an EM activity is helpful when capturing, delimiting, and analyzing the initial problem situation and deciding on a course of action. In such cases EM is mostly used as a problem solving and communication tool. The enterprise model created during this type of modeling is used for documenting the discussion and the decisions made. The main characteristics of this purpose are that the company does not intend to use the models for further development work and that the modeling activity has been planned to be only a single iteration. In some cases this situation changes into one of the other EM purposes because the organization sees EM as beneficial or the problem turns out to be more complex than initially thought and more effort is needed for its solution.

In [3] we analyze the different purposes in order to formulate requirements for: input models and documentation needed for the project, enterprise models to be developed, EM language needed to document the modeling product, the EM process, EM tool to support the project, as well as factors of model quality that the project should consider. These requirements are described in Table 2 in relation to the different EM purposes. 
Table 2. Requirements on EM [3]

\begin{tabular}{|c|c|c|c|c|c|c|}
\hline $\begin{array}{l}\text { Purpose of } \\
\text { EM }\end{array}$ & $\begin{array}{l}\text { Input } \\
\text { models and } \\
\text { documen- } \\
\text { tation }\end{array}$ & $\begin{array}{l}\text { Models to be } \\
\text { developed }\end{array}$ & $\begin{array}{l}\text { EM } \\
\text { language } \\
\text { require- } \\
\text { ments }\end{array}$ & $\begin{array}{l}\text { EM } \\
\text { process } \\
\text { require- } \\
\text { ments }\end{array}$ & $\begin{array}{l}\text { EM tool } \\
\text { require- } \\
\text { ments }\end{array}$ & $\begin{array}{l}\text { Model quality } \\
\text { requirements }\end{array}$ \\
\hline \multicolumn{7}{|c|}{ Develop the business } \\
\hline $\begin{array}{l}\text { Develop } \\
\text { visions and } \\
\text { strategy }\end{array}$ & $\begin{array}{l}\text { Existing } \\
\text { models and } \\
\text { other } \\
\text { business } \\
\text { "blueprints" }\end{array}$ & $\begin{array}{l}\text { Business oriented } \\
\text { models, e.g. Goal } \\
\text { Model (GM), } \\
\text { Concept Model } \\
\text { (CM), Business } \\
\text { Proc. Model } \\
\text { (BPM), Actor } \\
\text { Model (AM), inter- } \\
\text { model links } \\
\end{array}$ & $\begin{array}{l}\text { Notation that } \\
\text { domain } \\
\text { stakeholders } \\
\text { understand }\end{array}$ & $\begin{array}{l}\text { Participa- } \\
\text { tory }\end{array}$ & $\begin{array}{l}\text { Plastic wall, } \\
\text { simple } \\
\text { documenting } \\
\text { tools }\end{array}$ & $\begin{array}{l}\text { Understanda- } \\
\text { bility, } \\
\text { correctness, } \\
\text { simplicity, } \\
\text { flexibility }\end{array}$ \\
\hline $\begin{array}{l}\text { Design/ } \\
\text { Redesign } \\
\text { the } \\
\text { business }\end{array}$ & $\begin{array}{l}\text { Vision and } \\
\text { strategy } \\
\text { models and } \\
\text { other kinds of } \\
\text { business } \\
\text { "blueprints" }\end{array}$ & $\begin{array}{l}\text { Business oriented } \\
\text { models, e.g. as } \\
\text { above as well as } \\
\text { inter-model links }\end{array}$ & $\begin{array}{l}\text { Established } \\
\text { notation that } \\
\text { domain } \\
\text { stakeholders } \\
\text { understand }\end{array}$ & $\begin{array}{l}\text { Participa- } \\
\text { tory } \\
\text { involving } \\
\text { multiple } \\
\text { stake- } \\
\text { holder } \\
\text { groups }\end{array}$ & $\begin{array}{l}\text { Plastic wall, } \\
\text { EM tools that } \\
\text { makes it } \\
\text { possible to } \\
\text { seamlessly } \\
\text { move to } \\
\text { requirements } \\
\text { analysis and } \\
\text { IS design } \\
\end{array}$ & $\begin{array}{l}\text { Complete- } \\
\text { ness, } \\
\text { correctness, } \\
\text { flexibility, } \\
\text { integration, } \\
\text { understanda- } \\
\text { bility, usability }\end{array}$ \\
\hline Develop IS & $\begin{array}{l}\text { Business } \\
\text { oriented } \\
\text { models }\end{array}$ & $\begin{array}{l}\text { IS architecture } \\
\text { models as well as } \\
\text { links with } \\
\text { business oriented } \\
\text { models }\end{array}$ & $\begin{array}{l}\text { Enough } \\
\text { formality and } \\
\text { precision to } \\
\text { allow } \\
\text { modeling of } \\
\text { complex } \\
\text { facts }\end{array}$ & $\begin{array}{l}\text { Partly } \\
\text { participa- } \\
\text { tory and } \\
\text { partly } \\
\text { analyst } \\
\text { driven }\end{array}$ & $\begin{array}{l}\text { Plastic wall, } \\
\text { EM tools or } \\
\text { CASE tools } \\
\text { depending } \\
\text { on the } \\
\text { development } \\
\text { approach }\end{array}$ & $\begin{array}{l}\text { Complete- } \\
\text { ness, } \\
\text { correctness, } \\
\text { flexibility, } \\
\text { integration, } \\
\text { usability }\end{array}$ \\
\hline \multicolumn{7}{|c|}{ Ensure the quality of business operations } \\
\hline $\begin{array}{l}\text { Ensure } \\
\text { acceptance } \\
\text { for business } \\
\text { decisions }\end{array}$ & $\begin{array}{l}\text { Various types } \\
\text { of business } \\
\text { "blueprints" } \\
\text { (e.g. } \\
\text { Balanced } \\
\text { Scorecard) }\end{array}$ & $\begin{array}{l}\text { Business oriented } \\
\text { models (GM, CM, } \\
\text { BPM, ARM, BRM) } \\
\text { as well as inter- } \\
\text { model links }\end{array}$ & $\begin{array}{l}\text { Notation that } \\
\text { domain } \\
\text { stakeholders } \\
\text { understand }\end{array}$ & $\begin{array}{l}\text { Participa- } \\
\text { tory } \\
\text { involving } \\
\text { knowledge } \\
\text { bearers } \\
\text { and users }\end{array}$ & $\begin{array}{l}\text { Plastic wall, } \\
\text { simple tools, } \\
\text { tools for } \\
\text { presentation } \\
\text { of models to } \\
\text { a wider } \\
\text { audience } \\
\text { (e.g. web- } \\
\text { based tools) }\end{array}$ & $\begin{array}{l}\text { Complete- } \\
\text { ness, } \\
\text { correctness, } \\
\text { integration, } \\
\text { simplicity, } \\
\text { understanda- } \\
\text { bility, usability }\end{array}$ \\
\hline $\begin{array}{l}\text { Maintain } \\
\text { and share } \\
\text { knowledge } \\
\text { about the } \\
\text { business }\end{array}$ & $\begin{array}{l}\text { Business } \\
\text { models (GM, } \\
\text { CM, BPM, } \\
\text { ARM, BRM), } \\
\text { inter-model } \\
\text { links } \\
\end{array}$ & $\begin{array}{l}\text { "Cleaned" models } \\
\text { that make sense } \\
\text { to a wider } \\
\text { audience }\end{array}$ & $\begin{array}{l}\text { Simple and } \\
\text { intuitive } \\
\text { modeling } \\
\text { language }\end{array}$ & $\begin{array}{l}\text { Partly } \\
\text { participa- } \\
\text { tory, partly } \\
\text { analyst } \\
\text { driven }\end{array}$ & $\begin{array}{l}\text { EM tools with } \\
\text { web interface }\end{array}$ & $\begin{array}{l}\text { Correctness, } \\
\text { integration, } \\
\text { understanda- } \\
\text { bility, usability }\end{array}$ \\
\hline \multicolumn{7}{|c|}{ Use EM as a business problem solving tool } \\
\hline $\begin{array}{l}\text { To analyze } \\
\text { and solve a } \\
\text { specific } \\
\text { problem or } \\
\text { task }\end{array}$ & $\begin{array}{l}\text { Initial problem } \\
\text { statement } \\
\text { and other } \\
\text { relevant } \\
\text { document- } \\
\text { tation }\end{array}$ & $\begin{array}{l}\text { Business oriented } \\
\text { models (GM, CM, } \\
\text { BPM, ARM, BRM) } \\
\& \text { inter-model } \\
\text { links }\end{array}$ & $\begin{array}{l}\text { Notation that } \\
\text { domain } \\
\text { stakeholders } \\
\text { understand }\end{array}$ & $\begin{array}{l}\text { Participa- } \\
\text { tory } \\
\text { involving } \\
\text { multiple } \\
\text { stake- } \\
\text { holder } \\
\text { groups }\end{array}$ & $\begin{array}{l}\text { Plastic wall, } \\
\text { simple } \\
\text { documenting } \\
\text { tools }\end{array}$ & $\begin{array}{l}\text { Correctness, } \\
\text { flexibility, } \\
\text { understanda- } \\
\text { bility }\end{array}$ \\
\hline
\end{tabular}




\section{Core Competencies in Enterprise Modeling Projects}

Previous research [4] has identified three levels of EM practitioner competency:

- Ability to model, more specifically, to construct an Enterprise Model which is syntactically correct according to the used EM language and in a reasonable way reflects the domain and problem in question.

- Ability to facilitate modeling sessions - being able to lead a group of domain experts in creating/refining an Enterprise Model and doing it in such a way that the group's knowledge and abilities work together to create a high quality model.

- Ability to lead EM projects towards fulfilling their goals and making the best of the project resources.

We claim that in order to target the main challenge of the EM process, which is to produce an EM outcome that is fit for its intended purpose, we need to consider a set of essential core competencies. In [3] we have analyzed a generic EM process in order to identify essential competencies related to its activities. The process contained the main activities depicted in Table 3.

Table 3. Activities in EM (adapted from [3])

Define scope and objectives of the modeling project
Plan for project activities and resources
Plan for modeling session
Gather and analyze background information
Interview modeling participants
Prepare modeling session
Conduct modeling session
Write meeting minutes
Analyze and refine models
Present the results to stakeholders

The identified competencies were found to fall into two categories:

1) Competencies related to modeling

- ability to model, including assessing and improving model quality according to the EM purpose and

- ability to facilitate participatory modeling sessions.

2) Competencies related to setting up and managing EM projects

- ability to select an appropriate EM approach and tailor it in order to fit the situation at hand

- ability to interview involved domain experts

- ability to define a relevant problem

- ability to define requirements on the results

- ability to establish a modeling project

- to adjust a presentation of project results and issues related to them to various stakeholders

- ability to navigate between the wishes of various stakeholders while upholding the EM project goal

- ability to assess the impact of the modeling result and the modeling process in the organization 
In the following, these core competencies will form the baseline for discussing more specific competencies that we claim are necessary to fulfill the different purposes of EM. Note that the competences only relate to the purposes described in Section 4 and EM activities listed in table 3.

\section{Purpose Driven Refinement of Competencies in EM Projects}

EM practitioners need the core abilities to model and to facilitate modeling sessions to effectively fulfill any of the EM purposes. Hence we will only discuss these abilities further if an additional sub-set of abilities are specifically needed. The same holds also for competencies related to setting up and managing EM projects. In the following sections we will discuss each of the EM purposes with respect to the more specific competency needed to fulfill this purpose.

At this stage of research we cannot claim to be complete in any way. Rather we see this as another step towards fully developed competency profiles for EM practitioners at different levels of experience and skill.

\subsection{Develop Visions and Strategy}

Ability to model, including assessing and improving model quality according to the EM purpose. In addition to the core abilities to model and to facilitate modeling sessions this EM purpose also requires specific modeling abilities to model on a high level of abstraction where initially the enterprise model is not internally connected and may appear to be consisting of "small islands". The main challenge here is to guide the modeling work towards a certain direction. This might be hard because a part of strategy development is to allow the group to explore different options to a certain degree. The facilitator, however, needs to have the ability to see a certain "path" in the models and steer the modeling participants from drifting off course, i.e. discussing peripheral problems and defining goals that are plainly unrealistic. This situation requires the practitioner to deal with a large degree of uncertainty while demonstrating confidence to the participants in the group.

Regarding competencies related to setting up and managing modeling projects the following specifics should be paid attention to:

Ability to select an appropriate EM approach and tailor it in order to fit the situation at hand. For strategy development there exist a number of suitable development approaches that the modeling practitioner needs to be reasonably knowledgeable about. The modeling participants might often be familiar with a specific modeling language and notation. In this case this language should be preferred instead of introducing a new one. Importing a strategy development approach into EM in most cases implies defining new "inter-model" links with the existing components in the enterprise model and/or defining synonyms among modeling components. This requires deep knowledge about the meta-models and intentions of the involved methods.

Ability to define a relevant problem. The ability to define a relevant problem goes hand in hand with the ability to facilitate. The problem might be defined relatively 
vaguely, e.g. to find the real problem. Nevertheless the EM practitioner should have the ability to define at least general boundaries for it.

Ability to navigate between the wishes of various stakeholders while upholding the EM project goal. Deciding on the direction of an organization influences an organization more than short-term decisions. Therefore, the risk of having to deal with various hidden agendas from stakeholders is imminent. Also, these stakeholders often have an influential position in the organization. This means that the modeling practitioner needs to be listening and diplomatic while demonstrating that she/he is the person in charge of the EM project. Taking this role requires experience and knowledge about how organizational cultures function as well as patience, an agreeable personality and a firm but pedagogical way of communicating.

Ability to assess the impact of the modeling result and the modeling process in the organization. Being able to assess the impact of a vision or a strategy requires some experience from both successful and unsuccessful processes of implementing strategies, since the degree of uncertainty can be quite high.

\subsection{Design/Redesign the Business}

Ability to model, including assessing and improving model quality according to the EM purpose. To fulfill this purpose, the EM practitioner should be able to assess that the models have enough quality to be possible to implement under the conditions that exist or will exist in the business at hand. This requires some previous experience from being involved in e.g. implementing processes in an organization. One important aspect here is to be able to assess not only the practical implications of change but also the cultural implication of change.

Ability to facilitate participatory modeling sessions. When designing/redesigning the business one of the main challenges is to avoid polishing the current way of thinking and working. The EM practitioner should be able to support the creativity of the group while maintaining upholding a critical view on the resulting models.

Specific competencies related to setting up and managing EM projects are as follows:

Ability to interview involved domain experts. Following the previous discussion, the EM practitioner should be able to assess the ability of potential modeling participants to think creatively and out of the box and to make sure that some people in the group are also "critical thinkers".

Ability to define requirements on the results. Often projects like this requires that different types of models are developed. The EM practitioner should, therefore, be able to define how the whole project sticks together and how each model contributes to bigger picture. Changes in the target area of the project could also influence other areas of the business. This means that the requirements on the result must be related to an even bigger picture that constitutes the surrounding organization and sometimes partner organizations. Requirements must be defined such that the result can be implemented afterwards. Putting this complicated "puzzle" together requires a high level of experience and skill from the EM practitioner. 
Ability to establish a modeling project. An important aspect of establishing an EM project with this purpose is to negotiate authority for change. Both the EM project leader (EM practitioner) and the modeling group/s involved must feel that they are authorized to make design decisions that take into account the goals and constraints of the project. This means that the EM practitioner must be able to identify which authorities are needed, identify the involved decision-makers and negotiate the proper authorities. Sometimes it happens that decision-makers go back on what they have approved, and then the EM practitioner will need to be able to either negotiate maintained authority or re-define the scope of the project.

Ability to navigate between the wishes of various stakeholders while upholding the EM project goal. All processes that involve change will cause different kinds resistance in the organization. Therefore, the risk of having to deal with various hidden agendas from stakeholders is imminent. This means that the modeling practitioner needs to be listening and diplomatic while demonstrating that she/he is the person in charge of the EM project. Taking this role requires experience and knowledge about how organizational cultures function as well as patience, an agreeable personality and a firm but pedagogical way of communicating.

\subsection{Develop Information Systems}

Ability to model. The specifics in relation to this purpose primarily focus on assessing and improving model quality according to the EM purpose of developing an IS. More specifically, the enterprise model should be created in such a way that it is possible to implement in a system. This might require increasing model formality. In this context the EM practitioner should understand the use of the models in the IS development project, e.g. how Concepts Model can be used as input for developing a database schema. Ultimately, the EM practitioner should have some experience from IS development projects, preferably from an operative point of view.

Ability to facilitate participatory modeling sessions. This purpose requires the ability to guide the modeling effort in such a way that a balance between the IT and business aspects is ensured. If one of the aspects dominates the other, the resulting solution risks being unsuitable for the organization.

Regarding competencies related to setting up and managing EM projects the following specifics should be paid attention to:

Ability to select an appropriate EM approach and tailor it in order to fit or be docked to the IS development process and its specific development methodology and (often) tools. In principle many modeling languages and tools can be used for this purpose and most often modeling language of one sub-model in the enterprise model can be replaced with another modeling language as long as the inter-model links remain in tact. E.g. EKD Goals Model notation in principle can be replaced with $i^{*}$ notation [8], and Concepts Model changed to UML Class Diagram [9]. The modeling practitioner should be able to perform such a method engineering task.

Ability to define requirements on the results. Modeling practitioner should be able to assess how are models used in the IS development process and when is the model complete enough to proceed to IS development activities. 
Ability to establish a modeling project. This EM purpose means that EM is used in a IS development project and perhaps not seen as a project in itself, but rather a set of intertwined activities. The modeling practitioner should be able understand the IS development methodology and design EM steps in a fitting way.

\subsection{Ensure Acceptance of Business Decisions}

For the EM purpose the main success criteria is that the decisions made during modeling and reflected in the model are accepted and taken up by the organization.

Ability to facilitate participatory modeling sessions. The facilitator should make sure that the group reaches consensus and real decisions that can be implemented in the organization. Furthermore, the facilitator should also make sure that the participants perceive the enterprise model as documentation of the decisions and the decisions as real allocated to real people for implementation.

Concerning competencies related to setting up and managing EM projects, the following are of relevance:

Ability to select an appropriate EM approach and tailor it in order to fit the situation at hand. All kinds of modeling tricks can be necessary, including breaking the methodology rules, modeling notation and using unconventional approaches. The modeling practitioner should be able to assess the impact of such actions on the modeling results and the process.

Ability to interview involved domain experts. This EM purpose might be associated with hidden agendas that need to be uncovered. Finding out how decisions are made in the organization and how they are implemented also is crucial. The modeling practitioner should have good listening skills because these issues can seldom be addressed with a straight question.

Ability to define requirements on the results. In this case the acceptance and the consensus could be seen more important than the model quality. Hence, it might sometimes be purposeful accepting low model quality if the group agrees with the decisions made.

Ability to navigate between the wishes of various stakeholders while upholding the EM project goal. This is particularly important because the project usually covers broader group of stakeholders than is possible to involve in modeling directly.

\subsection{Maintain and Share Knowledge about the Business}

For this purpose it is important to understand that sometimes existing models are used as input and sometimes models are created for the purpose of depicting how the business is carried out. In the latter case the modeling is about capturing the current state of affairs and ways of working.

Ability to model, including assessing and improving model quality according to the EM purpose. The models that are created for this purpose have a specific target, which is to convey a message and also to instruct a diverse group of stakeholders. 
This means that the understandability of models is essential, which in this case is a critical aspect of model quality together with correctness. For the EM practitioner this means that the ability to become knowledgeable about the characteristics and needs of the target groups is important. Listening and communication skills are essential here.

The following specifics should be paid attention to concerning competencies related to setting up and managing EM projects:

Ability to select an appropriate EM approach and tailor it in order to fit the situation at hand. In this case, the modeling language should either be familiar to the stakeholders or be simple enough to understand without prior knowledge of the language. The EM practitioner should have enough knowledge about modeling languages to be able to balance quality aspects such as correctness of the models in terms of state of affairs of the business with the quality aspect of understandability.

Ability to define requirements on the results. This ability relates, again, to the understandability of models. Also, in order to be able to properly define the requirements, the EM practitioner should have some knowledge relating to organizational learning. This is further discussed under the ability to assess the impact of the modeling result below. One important aspect of this ability is setting up for maintenance of models, because the business changes and the models should change accordingly. This means that the EM practitioners needs to be knowledgeable about different tools that can be used to document and maintain models as well as be able to set up a feasible maintenance process. More on what is needed to keep models "live" is available in [7 and 10] and on using Active Knowledge Models in organizations see [11].

Ability to adjust a presentation of project results and issues related to them to various stakeholders. Presentation of the resulting models is one of the key issues for this purpose. Sometimes the models themselves may not be the best way to present the organizational knowledge and some alternative ways of presentation must be devised. Providing background information and connecting models to this can be one potential approach. Another approach could be to develop simulations based on the models. The ability to understand the conditions under which the models/information makes sense to the intended stakeholder groups is essential here. Pedagogical knowledge is also helpful, together with knowledge about how different media can enhance the message that is being conveyed

Ability to assess the impact of the modeling result and the modeling process in the organization. The ultimate desired impact of fulfilling this purpose is that organizational learning is created. To lead a modeling project with this purpose the EM practitioner should preferable have some knowledge and experience from fields that address organizational learning, such as e.g. Knowledge Management.

\subsection{Use EM to Analyze and Solve a Specific Business Problem}

EM projects with this purpose are usually quite short and compact in time, e.g. they should be done within a week. More about what happens in early phases of EM is available in [12]. For this purpose the modeling competencies do not have specific areas or concerns, but competencies related to setting up and managing EM projects have the following specific issues to consider: 
Ability to select an appropriate EM approach and tailor it in order to fit the situation at hand. In this case simple EM languages and notations should be preferred because there will be no time to familiarize the participants with the modeling approach. Also, using the approaches that the organization already has should be preferred. The EM practitioner should be able to find out what the organization has in terms of existing approaches and assess how it can be used in an EM project.

Ability to interview involved domain experts. Interviewing needs in this context to follow a tight schedule, since time for planning is usually very restricted. The interviews should, however, not be done in a haphazard way, i.e. the EM practitioner should be able to follow a predefined interview script and keep the schedule.

Ability to define a relevant problem. Even in short projects such as these the problems put forward by the domain experts can be quite large and many. The modeling practitioner should be able to find the relevant problem/s in a cluster of problems.

Ability to define requirements on the results. In this situation there are often very strict constraints in terms of time and other resources. E.g., there may only be time for one modeling session. This requires the modeling practitioner to be realistic in terms of what can be achieved and to communicate this to the problem owner, especially in cases, where the resource constraints put at risk achieving the expected result.

Ability to assess the impact of the modeling result and the modeling process in the organization. Since the EM project happens so quickly in the organization the difficulty is to make sure that someone will actually take up the result and implement it. This needs to be addressed in the project negotiation and planning phase, for example, by inviting modeling participants that can support implementation.

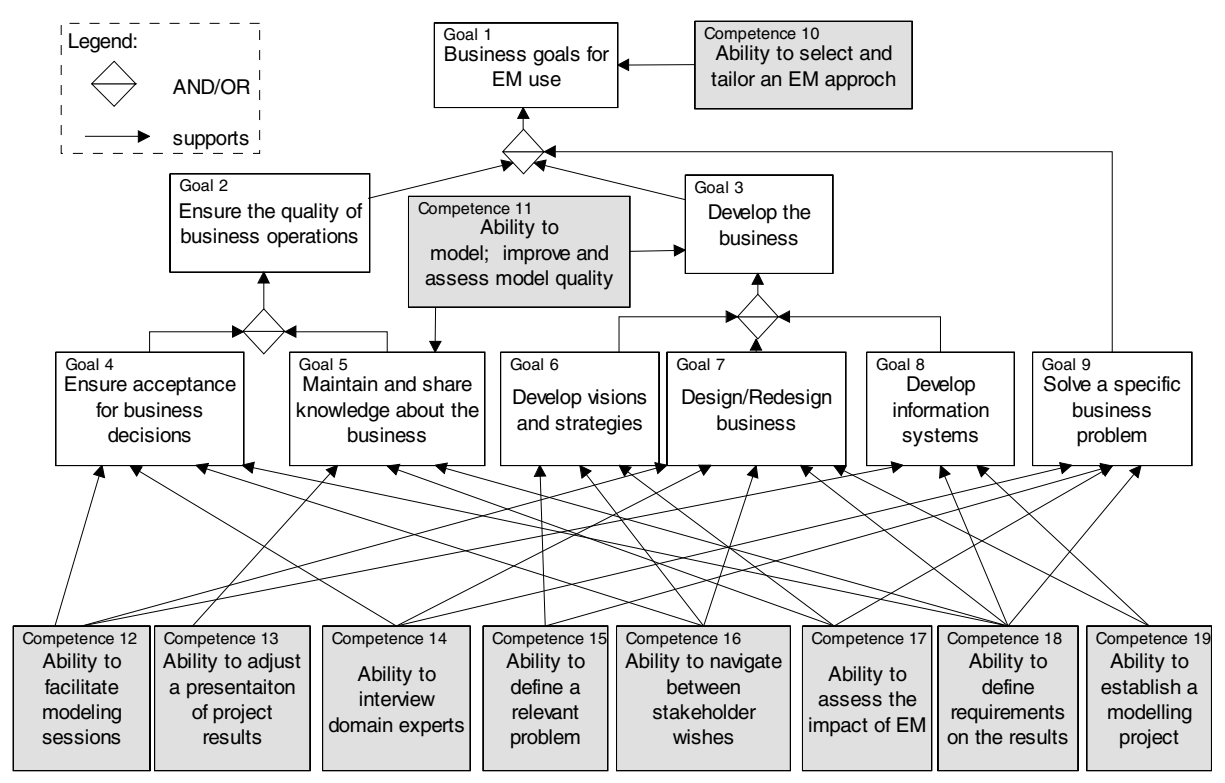

Fig. 2. EM goals aligned with supporting competencies (shaded) 


\subsection{Discussion}

Relationships between the EM goals and competencies discussed in the previous section are shown in figure 2. In the paper we have only focused on an EM practitioner who is responsible for managing part of or the whole EM project process towards effectively achieving its goals. Looking at the refined result we see that a few of the core competencies support more or less all purposes in a specific way:

- Ability to model, including assessing and improving model quality according to the EM purpose.

- Ability to select an appropriate EM approach and tailor it to fit the situation at hand.

- Ability to define requirements on the results

- Ability to assess the impact of the modeling result and the modeling process in the organization.

- Ability to navigate between the wishes of various stakeholders while upholding the EM project goal.

\section{$7 \quad$ Related Work}

The current state of the art is that scholars in EM formulate a set of guidelines and various dos and don'ts for conducting the EM or business modeling process (c.f., for example, 11, 13 and 14). Most of these recommendations are centered on the modeling activities and relatively few guidelines address the preparatory stages of the modeling process. The skills formulated in this paper are needed in order to successfully apply the guidelines given in the literature,

Beyond EM and Requirements Engineering there also are other relevant areas that need to be considered when planning for EM projects such as general competences and soft skills of project management, competences specific for IT projects (c.f. e.g. 15 and 16) and consulting (see [17]). [18] presents a set of general characteristics of agile modelers which can also be seen as relevant skill-sets to EM projects.

Facilitation is a general technique used in group processes for a wide variety of purposes not only in EM (see further e.g. [19] and International Association for Facilitators (IAF) http://www.iaf-world.org). This ability is very much based on knowledge about the effects of modeling, the principles of human communication and socialization (especially in groups), as well as the conditions of human learning and problem solving (cognition).

In this paper we have been inspired by modeling of organizational tasks related to their necessary competencies that we performed during the MAPPER project [12]. However a more ontology driven approach as, for instance, presented in [20] should be used in the future to develop more fine-grained competency indicators and values.

\section{Concluding Remarks and Future Work}

The area of EM is to a large extent practice driven. Scientific theories targeting the practice of EM are lacking. This paper, together with [2] and [3], are exploratory 
attempts to provide building blocks for theories addressing the preconditions of successful EM.

The objective of this paper is to further refine a set of previously defined core competencies for the EM practitioner. The refinement is based on the competency needs that are related to different purposes of EM.

As a limitation we would like to point out that the current set of competences only address the EM process to be carried out for different purposes. Hence it should be seen as a subset of competences for business consultants, requirements analysis, and project managers. Furthermore, the competences are derived from applying EM in a participatory way in an organizational context. Also, the process of collecting and analyzing data from a large number of sources could potentially be a threat to validity. We have tried to minimize this risk by being clear about how intermediate results were synthesized. The current competence profile should be seen as a proposal to be tested and validated in future research and practice.

The refinements emphasize that successful management of modeling projects, large or small, is heavily dependent on experience, not only from modeling but also from a broader set of areas such as implementation of strategies, change management, and systems development. In earlier papers we have concluded that this is not something for the novice. Hence, there needs to be at least two competency profiles for the EM practitioner: 1) The beginner EM practitioner and 2) the expert EM practitioner. We also believe that these profiles need to define the kind of roles that these two profiles can take on, both in the actual modeling and in the management of EM projects. The definition of these two profiles is needed to construct effective training, both at university level as well as in-practice training/mentoring to become an expert EM practitioner. One argument for this is that it is difficult to know which competency should be developed at which stage of maturity in the EM expert. E.g., confusing the novice with issues that only a more experienced EM practitioner can understand is not particularly effective. Looking at EM education and training, particularly in the university context, it is mostly focused on the ability to model. Often it is assumed that with that ability comes, implicitly, the ability to facilitate modeling sessions and particularly to manage EM projects. Based on our research we find that this is clearly not the case.

Finally, the fact that the issue of implementing the EM result is evident in several cases also emphasizes that an important characteristic of successful EM is that the modeling result is actually used.

\section{References}

1. Persson, A., Stirna, J.: An explorative study into the influence of business goals on the practical use of Enterprise Modelling methods and tools. In: Tenth International Conference on Information Systems Development (ISD 2001), Royal Holloway, University of London, September 5-7 (2001)

2. Bubenko Jr., J.A., Persson, A., Stirna, J.: An Intentional Perspective on Enterprise Modeling. In: Salinesi, C., Nurcan, S., Souveyet, C., Ralyté, J. (eds.) An Intentional Perspective on Enterprise Modeling. Springer (2010) ISBN 978-3-642-12543-0 
3. Persson, A., Stirna, J.: Towards Defining a Competence Profile for the Enterprise Modeling Practitioner. In: van Bommel, P., Hoppenbrouwers, S., Overbeek, S., Proper, E., Barjis, J. (eds.) PoEM 2010. LNBIP, vol. 68, pp. 232-245. Springer, Heidelberg (2010) ISBN 978-3-642-16781-2

4. Persson, A.: The Practice of Participatory Enterprise Modelling - a Competency Perspective. In: Johannesson, P., Söderström, E. (eds.) Information Systems Engineering from Data Analysis to Process Networks, pp. 129-157. Idea Group Inc. (2008) ISBN-13: 978-1-59904-567-2

5. Bubenko Jr., J.A., Persson, A., Stirna, J.: User Guide of the Knowledge Management Approach Using Enterprise Knowledge Patterns. Deliverable D3, IST Programme project Hypermedia and Pattern Based Knowledge Management for Smart Organisations, project no. IST-2000-28401, Royal Institute of Technology, Sweden (2001)

6. Glaser, B.G., Strauss, A.L.: The Discovery of Grounded Theory: Strategies for Qualitative Research. Weidenfeld and Nicolson, London (1967)

7. Stirna, J., Persson, A.: An Enterprise Modeling Approach to Support Creativity and Quality in Information Systems and Business Development. In: Halpin, T., Krogstie, J., Proper, E. (eds.) Innovations in Information Systems Modeling: Methods and Best Practices. IGI Global (2008) ISBN 978-1-60566-278-7

8. Yu, E.S.K., Mylopoulos, J.: From E-R to “A-R” - Modelling Strategic Actor Relationships for Business Process Reengineering. In: Loucopoulos, P. (ed.) ER 1994. LNCS, vol. 881, pp. 548-565. Springer, Heidelberg (1994)

9. Object Management Group (OMG), Unified Modeling Language (UML) 2.0 (2005)

10. Wesenberg, H.: Enterprise Modeling in an Agile World. In: Johannesson, P., Krogstie, J., Opdahl, A.L. (eds.) PoEM 2011. LNBIP, vol. 92, pp. 126-130. Springer, Heidelberg (2011)

11. Lillehagen, F., Krogstie, J.: Active Knowledge Modeling of Enterprises. Springer (2008) ISBN: 978-3-540-79415-8

12. Sandkuhl, K., Lillehagen, F.M.: The Early Phases of Enterprise Knowledge Modelling: Practices and Experiences from Scaffolding and Scoping. In: Stirna, J., Persson, A. (eds.) PoEM 2008. LNBIP, vol. 15, pp. 1-14. Springer, Heidelberg (2008) ISBN 978-3-54089217-5

13. Bridgeland, D.M., Zahavi, R.: Business Modeling: A Practical Guide to Realizing Business Value. Morgan Kaufmann (2009) ISBN: 978-0-12-374151-6

14. Lankhorst, M., et al.: Enterprise Architecture at Work: Modelling, Communication and Analysis, 2nd edn. Springer (2009) ISBN 978-3-642-01309-6

15. Suikki, R., Tromstedt, R., Haapasalo, H.: Project management competence development frameworkin turbulent business environment. Technovation 26, 723-738 (2006)

16. Gillard, S.: Soft Skills and Technical Expertise of Effective Project Managers. Issues in Informing Science and Information Technology 6 (2009)

17. Kaarst-Brown, M.L.: Five symbolic roles of the external consultant - Integrating change, power and symbolism. Journal of Organizational Change Management 12(6), 540-561 (1999)

18. Ambler, S.: Agile modeling: Effective practices for extreme programming and the unified process, 1st edn. John Whiley\& Sons Inc. (2002) ISBN 978-0471202820

19. Zavala, A., Hass, B.H.: The Art and Power of Facilitation: Running Powerful Meetings, Management Concepts. Inc., Vienna, USA (2008) ISBN 9781567262124

20. Albertsen, T., Sandkuhl, K., Seigerroth, U., Tarasov, V.: The Practice of Competence Modelling. In: van Bommel, P., Hoppenbrouwers, S., Overbeek, S., Proper, E., Barjis, J. (eds.) PoEM 2010. LNBIP, vol. 68, pp. 106-120. Springer, Heidelberg (2010) 